\title{
FLUID DYNAMICS ANALYSIS AND NUMERICAL STUDY OF A FLUID RUNNING DOWn a Flat SuRfaCe
}

\author{
Juan Carlos Beltrán-Prieto \& Karel Kolomazník
}
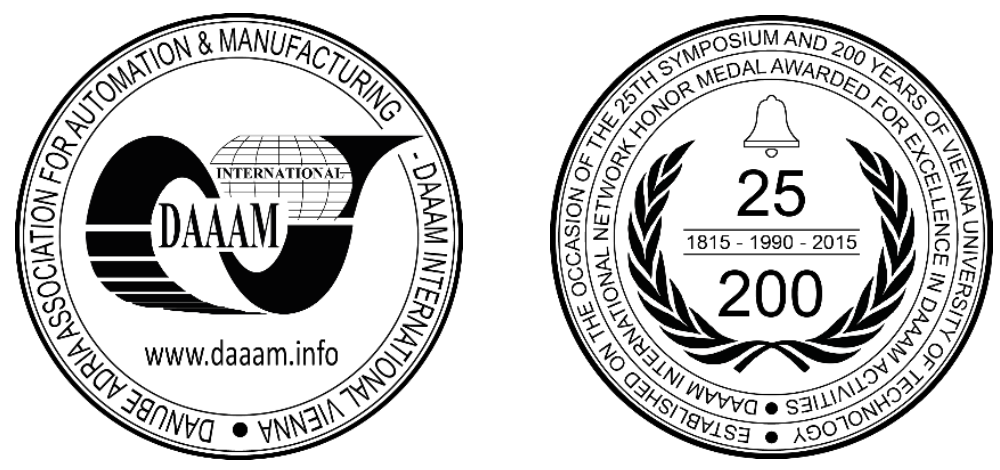

This Publication has to be referred as: Beltran-Prieto, J[uan] C[arlos] \& Kolomaznik, K[arel] (2018). Fluid Dynamics Analysis and Numerical Study of a Fluid Running Down a Flat Surface, Proceedings of the 29th DAAAM International Symposium, pp.0801-0810, B. Katalinic (Ed.), Published by DAAAM International, ISBN 978-3-90273420-4, ISSN 1726-9679, Vienna, Austria

DOI: $10.2507 / 29$ th.daaam.proceedings.116

\begin{abstract}
The case of fluid flowing down a plate is applied in several industrial, chemical and engineering systems and equipments. The mathematical modeling and simulation of this type of system is important from the process engineering point of view because an adequate understanding is required to control important parameters like falling film thickness, mass rate flow, velocity distribution and even suitable fluid selection. In this paper we address the numerical simulation and mathematical modeling of this process. We derived equations that allow us to understand the correlation between different physical chemical properties of the fluid and the system namely fluid mass flow, dynamic viscosity, thermal conductivity and specific heat and studied their influence on thermal diffusivity, kinematic viscosity, Prandtl number, flow velocity, fluid thickness, Reynolds number, Nusselt number, and heat transfer coefficient using numerical simulation. The results of this research can be applied in computational fluid dynamics to easily identify the expected behavior of a fluid that is flowing down a flat plate to determine the velocity distribution and values range of specific dimensionless parameters and to help in the decision-making process of pumping systems design, fluid selection, drainage of liquids, transport of fluids, condensation and in gas absorption experiments.
\end{abstract}

Keywords: Prandtl number; dynamic viscosity; heat transfer coefficient; fluid thickness; flowing down liquid

\section{Introduction}

The study of fluids in motion is a complex problem in which the parameter of viscosity plays an important role, however many of the most common analysis ignore the viscosity effects, by assuming that the liquid can be divided into several layers that overlap each other without finding any resistance. Actually this is far from being true, as tangential forces are present and sometimes in considerable amount that the running flow takes place with great difficulty, as it happens for example with very heavy oils. On the other hand, sometimes these forces are very small and the liquid flows easily, as it happens with fluids like water or alcohol. This resistance to flow is characterized by a typical coefficient of each substance, namely viscosity and it describes the internal friction of a moving fluid [1]. Dynamic viscosity can be measured using a rotational viscometer [2]. This instrument rotates a probe in the fluid sample and measure the force needed to turn the probe. 
Experimental data of running down fluids have shown the presence of three different flow regimes, classified according to the Reynolds dimensionless parameter $(R e)$, namely laminar flow (with and without considerable rippling) and turbulent flow. Accordingly, other important parameter in the study of fluids in motion is the transport heat coefficient of a liquid which can be estimated using the Nusselt number $(N u)$ and determined as $N u=C \cdot \operatorname{Pr}^{0.35} \operatorname{Re}^{m}$, where $C$ and $m$ are constants depending on the Reynolds number, $\operatorname{Pr}$ corresponds to Prandtl number, which correlates the ratio of momentum diffusivity or kinematic viscosity $\left(\mathrm{m}^{2} / \mathrm{s}\right)$ with the thermal diffusivity $\left(\mathrm{m}^{2} / \mathrm{s}\right)$. Accordingly, Reynolds number is defined by $\operatorname{Re}=(\bar{v} \delta \rho) / \mu$. In the previous formula, the parameters relate to the properties of the fluid, i.e. $\bar{v}$ correspond to the flow velocity of the fluid, $\delta$ the fluid thickness, $\rho$ is the density and $\mu$ the viscosity. The Reynolds number is the number that gives the characteristics of a fluid, since it is the quotient of inertial forces and viscous forces. Additionally, it allows characterizing the nature of the flow, that is, if it is a laminar or turbulent flow. In all flows there exists a value of this ratio for which the transition from laminar flow to turbulent flow occurs, usually referred to as the critical Reynolds number [3]. Correct understanding of the relationship between the aforementioned parameters is important because the theoretical study of flow systems is limited by the postulates and conditions of the system. Very often experiments are required to determine the flow regime in order to know if the flow will behave turbulent. Difficulties arise due to the nonlinear nature of the governing equations of fluids in motion [4].

The study of fluid in motion and running down fluids has been studied by several research groups. Hantsch and Gross reported the use of lattice Boltzmann methods to model the fluid flow assuming an isothermal two-phase flow described by the Shan-Chen model. Their approach was innovative since lattice Boltzmann methods were not previously reported for simulating fluids running down [5]. Miyara reported the use of marker and cell method for different dimensionless parameters (Prandtl, Reynolds, Weber, and Froude numbers) to study falling liquid films in vertical and inclined surfaces [6] and [7]. On the other hand, numerical studies on thin liquid films sheared by a gas flow have been reported by Lavalle et al., [8] who used a long-wave integral model, saving computational cost with respect to numerical simulation of the Navier-Stokes equations, which are frequently used to describe the motion of viscous fluids [9].

Furthermore, the simulation of turbulence near a freely deformable interface, including numerical simulations was reported by Fulgosi et al. They concluded that streaky structure over the deformable interface is less organized than over a rigid wall but the interfacial motion does not affect considerably the elongation of the streaks [8]. Other studies about fluids in motion by means of mathematical modeling though network profiles and boundary element method have been also reported previously [10] and [11] including the study of pressure distribution in fluid films, and calculation of fluid film thickness and temperature distribution [12], the development of an algorithm for nonisothermal two-phase flow with free surface and its corresponding validation with empirical, numerical and experimental data [13]. In spite of several efforts aimed to model running down fluids, less has been done on the evaluation of certain physical chemical properties of the fluid and the system and its effect on other fluid parameters, such as thermal diffusivity, kinematic viscosity, Prandtl number, flow velocity, fluid thickness, Reynolds number, Nusselt number, and heat transfer coefficient.

The basic problem in heat convection consist on determining the heat transfer coefficient $(\alpha)$ which allows further determination of heat flux or heat flow rate intensity. The analysis of convection is based on experimental data presented in the form of correlations. There are very few cases where it is possible to approach them analytically; however this method is not practical from the engineering point of view. Heat transfer coefficient can be determined following Nusselt correlation $(N u=\alpha \delta / \lambda)$ where the numerator represents the heat transfer by convection and the denominator the heat transfer by conduction. Here $\alpha$ is the heat transfer coefficient $\left(\mathrm{W} / \mathrm{m}^{2} \cdot K\right), \lambda$ the thermal conductivity $(W / m \cdot K)$ and $\delta$ the thickness $(m)$ [14]. For the estimation of Nusselt number, it is necessary to distinguish between forced and natural convection. In forced convection $N u$ is a function of the number of Reynolds $(R e)$ and Prandtl $(P r)$, $N u=f(R e, P r)$. In natural convection, $N u$ is a function of Grashof number $(G r)$ and Prandtl $(P r)$ or of the number of Rayleigh $(R a)$ and Prandlt since $R a=G r \operatorname{Pr}$. Thus $N u=f(\operatorname{Ra}, \operatorname{Pr})=f(G r, \operatorname{Pr})$ [15].

In order to determine the thermal power involved in convection, we need to define the conditions in which convection takes place (surface geometry, natural or forced convection, flow type) to select the appropriate correlation and with the known data from the system, the Nusselt number can calculated, followed by the heat transfer coefficient. Finally, the thermal power can be estimated following Newton's Law of cooling [16].

In the present paper, we analyze the problem of a fluid that is running down through a wall. For numerical analysis, physical chemical properties of the fluid and the system are known or can be determined, namely mass flow of fluid that is running down $(\mathrm{kg} / \mathrm{s})$, dynamic viscosity $(\mathrm{Pa} \cdot \mathrm{s})$, density $\left(\mathrm{kg} / \mathrm{m}^{3}\right)$, thermal conductivity $(\mathrm{W} / \mathrm{m} \cdot \mathrm{K})$, specific heat $(\mathrm{kJ} / \mathrm{kg} \cdot \mathrm{K})$, and wall width $(m)$. Taking this into consideration, it is possible to determine several fluid parameters, such as thermal diffusivity $\left(\mathrm{m}^{2} / \mathrm{s}\right)$, kinematic viscosity $\left(\mathrm{m}^{2} / \mathrm{s}\right)$, and Prandtl number. Additionally, we proceed to explain the variation of flow velocity $(\mathrm{m} / \mathrm{s})$, fluid thickness $(\mathrm{m})$, Reynolds number, Nusselt number, and heat transfer coefficient $\left(\mathrm{W} / \mathrm{m}^{2} \cdot K\right)$ according to the fluid physical properties and the system. 


\section{Numerical procedure and computational details}

\subsection{Assessment of kinematic viscosity and thermal diffusivity}

The description of the system under study is resented in Fig. 1. We consider that at surface-fluid interface, the fluid velocity and the velocity at which the surface moves is the same, and that there is no material going through the interface, i.e. no adsorption, absorption, dissolution, evaporation or chemical reactions and also the existence of a parabolic velocity distribution. Accordingly, we suppose that the fluid is steady and incompressible, with negligible entrance effects and smooth surface of the plate.

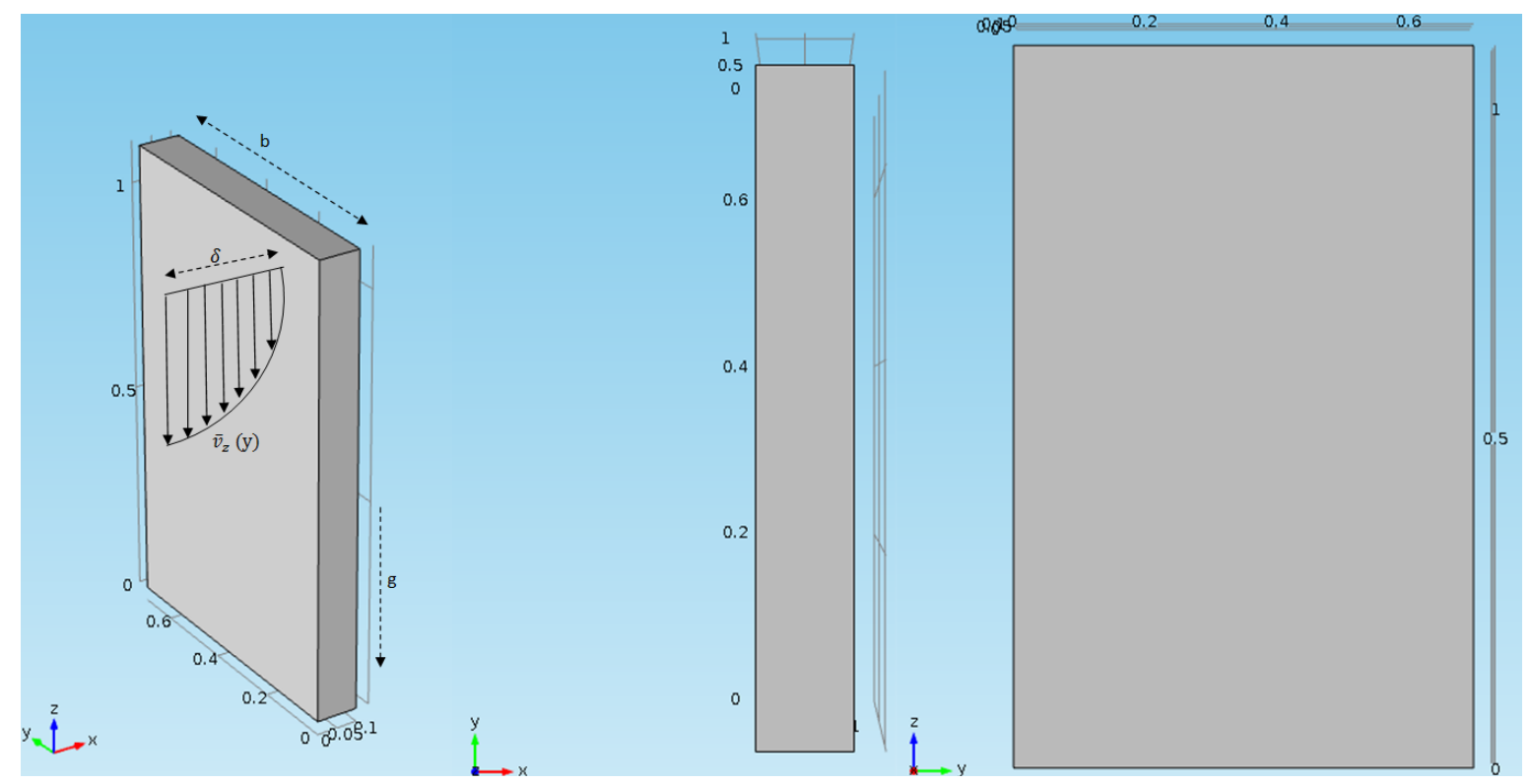

Fig. 1. Development of parabolic velocity profile in laminar flow for the system under study. Schematic diagram of the flow of a falling film

It is important to note that the kinematic viscosity represents the ratio between the dynamic viscosity and the density of the fluid [17]. This relationship can be observed in Fig. 2. Fluid viscosity is responsible for the development of the velocity boundary layer. No velocity boundary layer would be formed in the case of fluids with zero viscosity. Understanding of viscosity and density is very important in the industry, for example in the use and selection of pumps, because if a pump that offers a pressure of 10 bar has been selected without consideration of the properties of the pumped liquid (i.e. different viscosities and densities of the liquids), it is extremely likely that the pump selected will not do the required task, additionally, it may be too big, with very high acquisition and operation costs and would take up a lot of space. On the other hand, if the pump is too small, the required amount of liquid will not be pumped, and if the engine selected is too small for the job in question, it will burn or it is also possible that the electrical safety system will stop the pump. As a result, it is very clear that the viscosity of a fluid affects its behavior in a pump. However, it is a complex issue since the viscosity of the fluids can change depending on the existing conditions. There are four main types of fluids, each with a specific behavior despite its specific viscosity, namely Newtonian, dilatants, Bingham and Pseudo-plastic fluids. The viscosity is a parameter that affects the resistance to flow, which also affects the pumps. When a sticky and very viscous fluid is used, it will adhere to the surface and it will cost much more to remove it than if it were a little viscous fluid. The same happens in pumps, where there are impellers that are responsible for moving the fluid. This is a matter to consider in cases where fluids that adhere to the surface of the impeller (e.g motor oil) are used.

Accordingly, another parameter that is also important in the study of fluids is the thermal diffusivity $\left(\mathrm{m}^{2} / \mathrm{s}\right)$, which can be determined following expression (1):

$$
a=\frac{\lambda}{C_{p} \rho}
$$

where $\lambda$ is the thermal conductivity $(\mathrm{W} / \mathrm{m} \cdot \mathrm{K})$, and $C_{p}$ is the specific heat $(\mathrm{kJ} / \mathrm{kg} \cdot \mathrm{K})$. Fig. 3 describes the variation of thermal diffusivity at given values of density and thermal conductivity. We can see that thermal diffusivity is directly proportional to thermal conductivity but inversely proportional to density and specific heat. Specific heat can be measured with Differential Scanning Calorimetry (DSC) or using a calorimeter, thermal conductivity can be determined with a heat flow meter and the density from the properties of the fluid (mass and volume). Additionally, values of thermal conductivity of solid materials can be also affected by properties such as weight, water content and porosity. 


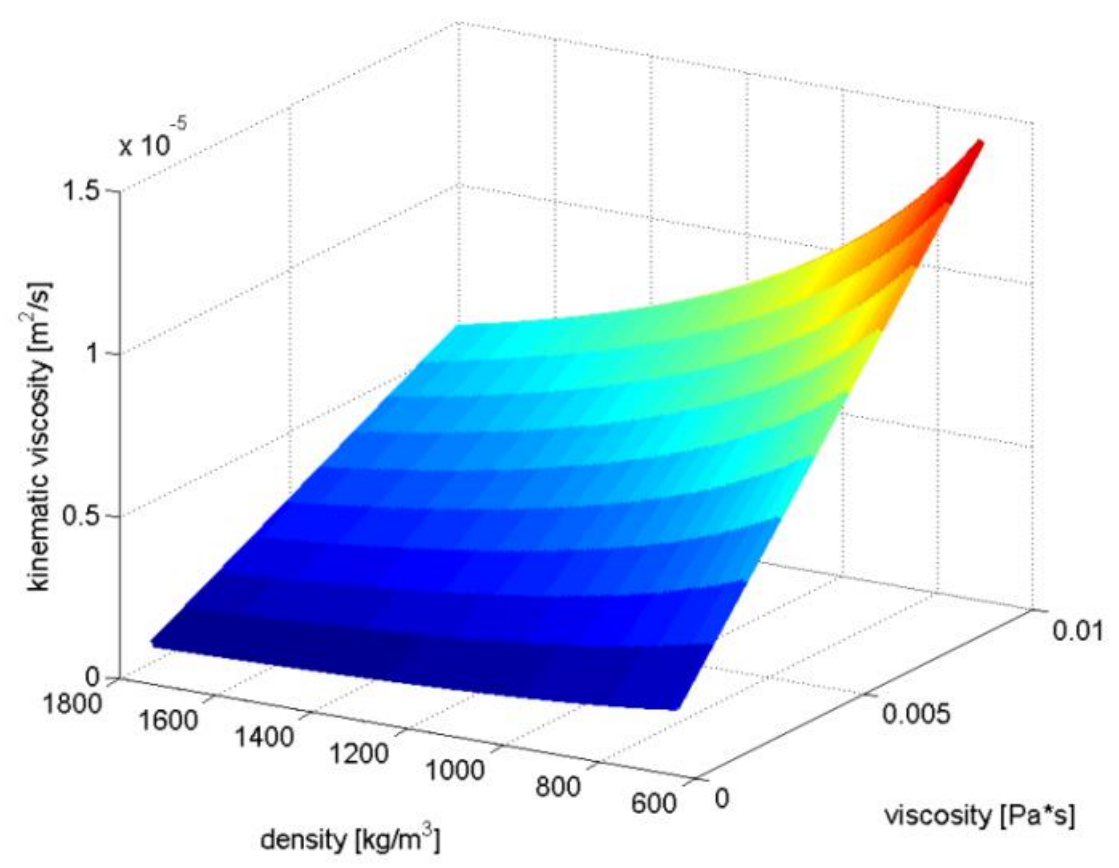

Fig. 2. Numerical evaluation of the influence of viscosity $(\mathrm{Pa} \cdot \mathrm{s})$ and density $\left(\mathrm{kg} / \mathrm{m}^{3}\right)$ on kinematic viscosity $\left(\mathrm{m}^{2} / \mathrm{s}\right)$
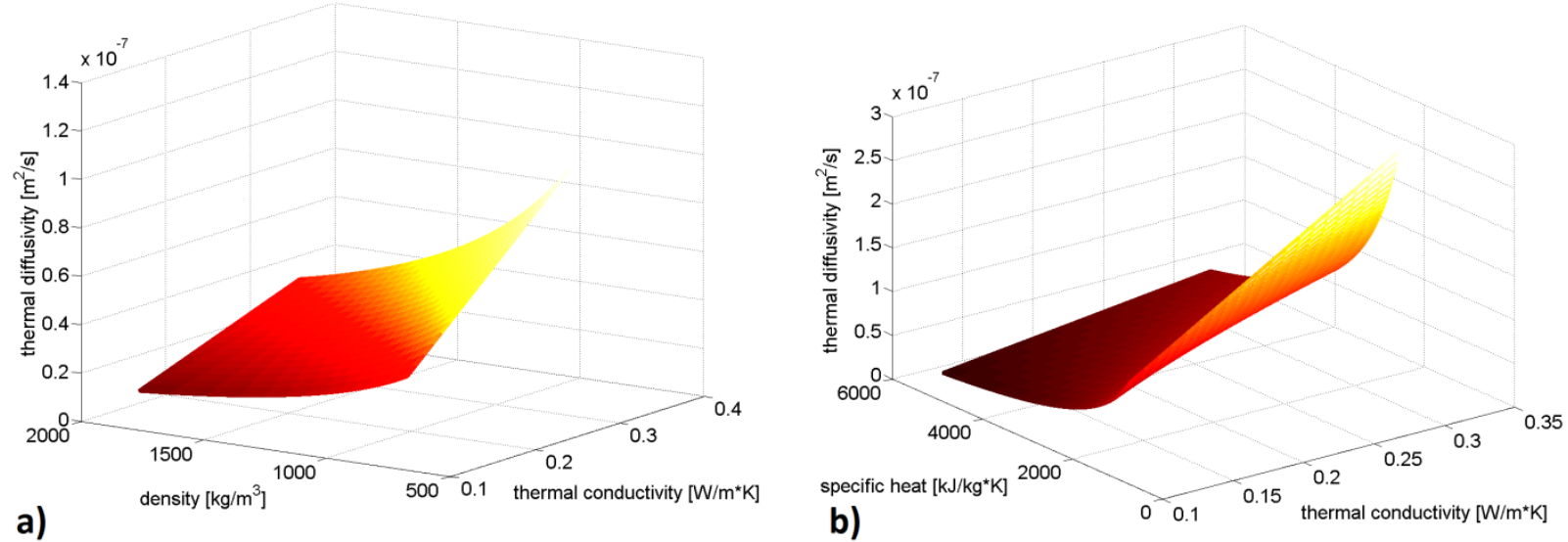

Fig. 3. a) Variation of thermal diffusivity $\left(\mathrm{m}^{2} / \mathrm{s}\right)$ at different values of thermal conductivity $(\mathrm{W} / \mathrm{m} \cdot \mathrm{K})$ and density $\left(\mathrm{kg} / \mathrm{m}^{3}\right)$ with constant specific heat $(\mathrm{kJ} / \mathrm{kg} \cdot \mathrm{K})$ b) Variation of thermal diffusivity $\left(\mathrm{m}^{2} / \mathrm{s}\right)$ at different values of thermal conductivity $(\mathrm{W} / \mathrm{m} \cdot \mathrm{K})$ and specific heat $(\mathrm{kJ} / \mathrm{kg} \cdot \mathrm{K})$ with constant density $\left(\mathrm{kg} / \mathrm{m}^{3}\right)$

Once the particular values of kinematic viscosity and thermal diffusivity are known, it is possible to determine the Prandtl number as described in (2). The influence of these parameters on the aforementioned dimensionless parameter can be seen in Fig. 4.

$$
\operatorname{Pr}=\frac{v}{a}
$$

The Prandtl number ranges from less than 0.01 for liquid metals to more than 100,000 for heavy oils. The $\operatorname{Pr}$ is of the order of 10 for water and around 1 for the gases. This indicates that both the amount of movement and heat are diffused by the fluid at a similar speed. Heat diffuses very quickly in liquid metals $(\operatorname{Pr}<1)$ and very slowly in the oils $(\operatorname{Pr} \gg>1)$ in relation to the amount of movement. This indicates that the thermal boundary layer is much thicker for liquid metals and much thinner for oils, in relation to the speed boundary layer. The thicker the thermal boundary layer is the faster the heat will diffuse into the fluid. 


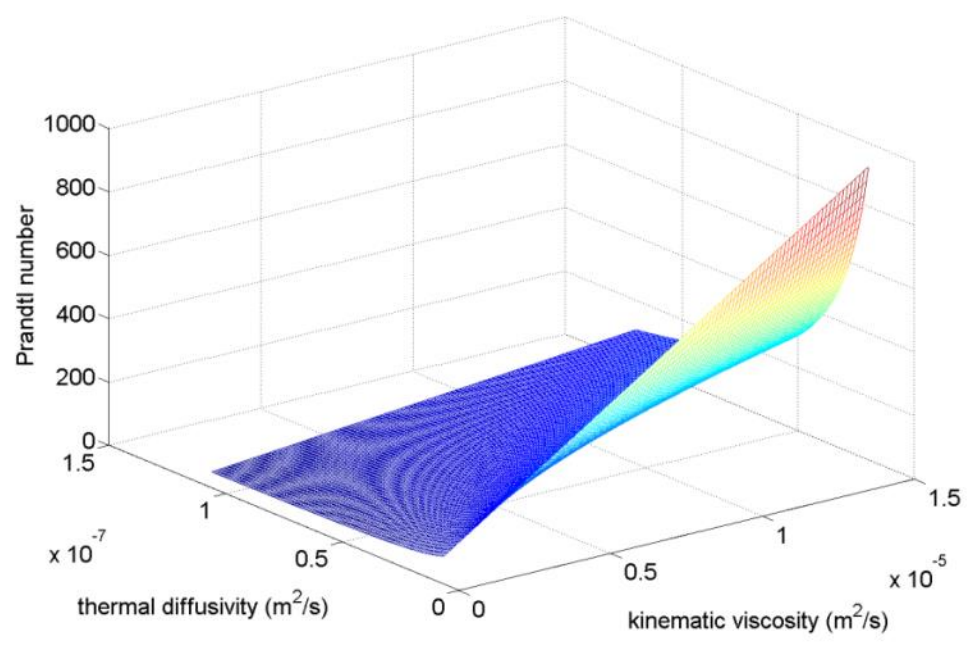

Fig. 4. Effect of kinematic viscosity $\left(\mathrm{m}^{2} / \mathrm{s}\right)$ and thermal diffusivity $\left(\mathrm{m}^{2} / \mathrm{s}\right)$ on Prandtl number (dimensionless) according to expression (2)

\subsection{Thickness and fluid velocity evaluation.}

In order to estimate the thickness of the fluid, we start by considering the definition of mass flow rate, which express the relationship between the density and the volumetric flow rate. This can be also expressed as $\dot{m}=\rho \dot{V}$, then it follows that $\dot{m}=\rho S \bar{v}$, where $S$ corresponds to the cross sectional vector area, which can be expressed as $S=b \cdot \delta$, where $b$ represents the wall width and $\bar{v}$ was previously defined as flow velocity, which is evaluated depending on the position as in (3)

$\bar{v}=\frac{\rho g}{\mu} \cdot \frac{1}{\delta} \int_{0}^{\delta}\left(\delta y-\frac{1}{2} y^{2}\right) d y$

The solution of previous integral leads to:

$\int_{0}^{\delta}\left(\delta y-\frac{1}{2} y^{2}\right) d y=\delta \int_{0}^{\delta} y d y-\frac{1}{2} \int_{0}^{\delta} y^{2} d y=\frac{\delta y^{2}}{2}-\left.\frac{1}{2} \frac{y^{3}}{3}\right|_{0} ^{\delta}=\frac{1}{3} \delta^{3}$

Then, substituting the result of the integral in (3) we have

$\bar{v}=\frac{\rho g}{\mu} \cdot \frac{1}{\delta}\left(\frac{1}{3} \delta^{3}\right)$

Thus, flow velocity can be evaluated as

$\bar{v}=\frac{\rho g \delta^{2}}{3 \mu}$

Substituting the expressions for $\overline{\mathrm{V}}$ and $\mathrm{S}$ in the definition of mass flow rate leads to

$\dot{m}=\rho S \bar{v}=\rho(b \cdot \delta)\left(\frac{\rho g \delta^{2}}{3 \mu}\right)=\frac{b \cdot \rho^{2} \cdot g \cdot \delta^{3}}{3 \mu}$

The previous expression allow us to determine the value of thickness of the film in the case that we know the mass flow rate, that is

$$
\delta=\sqrt[3]{\frac{3 \mu}{b \cdot \rho^{2} \cdot g}}
$$


As a model example, we can consider constant values for wall width and mass flow rate equal to $1 \mathrm{~m}$ and $0.01 \mathrm{~kg} / \mathrm{s}$ respectively to evaluate the variation of viscosity, density and thickness (Fig. 5a)). Density is evaluated in a range between $700 \mathrm{~kg} / \mathrm{m}^{3}$ to $1100 \mathrm{~kg} / \mathrm{m}^{3}$, which corresponds to a wide range of fluids, i.e. acetone (784 $\mathrm{kg} / \mathrm{m}^{3}$ ), propyl alcohol $\left(800 \mathrm{~kg} / \mathrm{m}^{3}\right)$, acetic acid $\left(1049 \mathrm{~kg} / \mathrm{m}^{3}\right)$, phenol $\left(1072 \mathrm{~kg} / \mathrm{m}^{3}\right)$, chloroform $\left(1489 \mathrm{~kg} / \mathrm{m}^{3}\right)$, etc. The values of viscosity are displayed in a range of values below $0.01 \mathrm{~Pa} \cdot \mathrm{s}$, corresponding also to a diversity of fluids like acetone $(0.000316 \mathrm{~Pa} \cdot \mathrm{s})$, chloroform (0.0005 Pa.s), acetic acid (0.001 Pa.s), phenol (0.008 Pa $\cdot$ ) or propyl alcohol $(0.0019 \mathrm{~Pa} \cdot \mathrm{s})$.
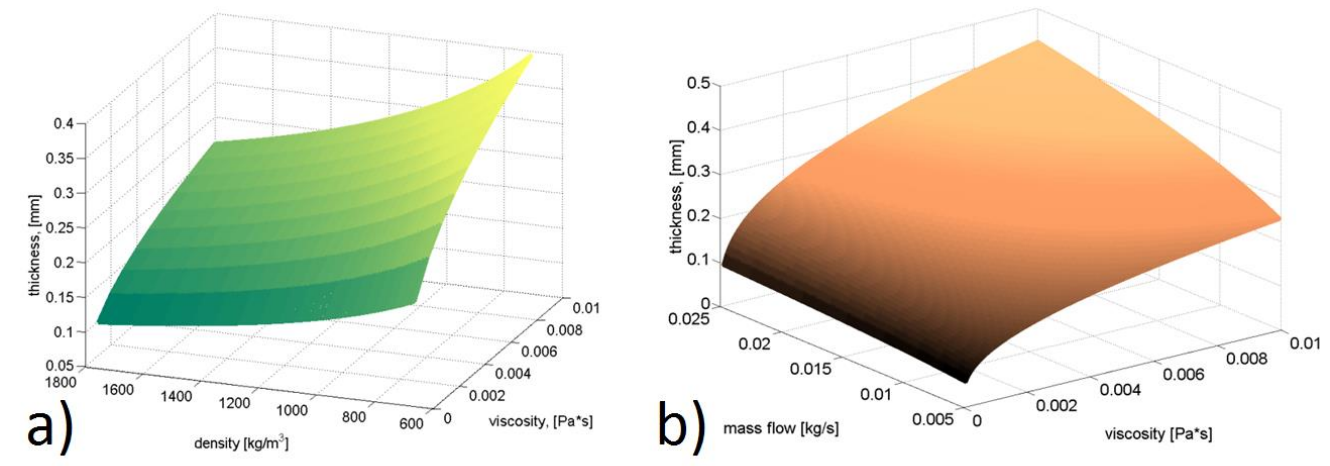

Fig. 5. a) Dependency of thickness $(\mathrm{mm})$ on viscosity $(\mathrm{Pa} \cdot \mathrm{s})$ and density $\left(\mathrm{kg} / \mathrm{m}^{3}\right)$ at constant mass flow $(\mathrm{kg} / \mathrm{s})$ and wall width. b) Variation of thickness $(\mathrm{mm})$ with different values of viscosity $(\mathrm{Pa} \cdot \mathrm{s})$ and mass flow $(\mathrm{kg} / \mathrm{s})$ at constant density $\left(\mathrm{kg} / \mathrm{m}^{3}\right)$ and wall width

This analysis allows us to understand the difference of using low density liquids, (e.g. acetone) with relatively low viscosity and fluids with higher viscosity and density (e.g. phenol). It is expected that for the former type of fluids the thickness of the film will have lower values in comparison to the latter type. Accordingly, at similar values of viscosity, there seems to be a proportional decrement of thickness as the density increases. On the other hand, the increment in viscosity has a more marked positive effect in increasing the thickness value at constant values of density.

Additionally, the variation of viscosity, mass flow, and thickness at constant values of density and wall width is presented in Fig. 5b). Here we can observe that at higher values of thickness are achieved when the viscosity and mass flow are higher. This is in agreement with the theoretical point of view, because the flow of fluid is retarded in the boundary layer as viscosity increases, therefore, the mass flow rate would acquire lower values at the surface of the solid in comparison to the case when there is absence of boundary layer. Following expression (6) it is possible to determine the velocity of fluid at different values of thickness and viscosity at constant values of density as shown in Fig. 6a). At extremely lower values of viscosity (i.e. $<0.0005 \mathrm{~Pa} \cdot \mathrm{s}$ ) the value of fluid velocity increases considerably. Higher velocity values are obtained when the thickness increases. The increment in fluid velocity causes an increment in the Reynolds number. Accordingly, since the Reynolds number is the ratio between the effect of inertia and viscous parameter. The increment means a lower influence of viscous effects and as a result, there will be a less extended zone of velocity variation. There are several parameters that affect the viscosity of a Newtonian fluid, such as temperature, pressure, and composition. Additionally, it is important to consider that for velocity effect, fluid deforms continuously and the rate of deformation is equivalent to the rate of velocity variation with respect to film thickness. If fluid resistance is less, the deformation will be higher. This will cause a greater velocity change in the fluid from boundary surface to top.

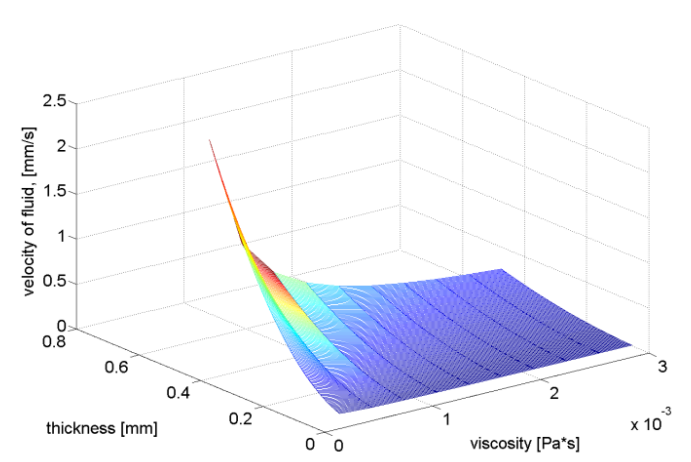

a)

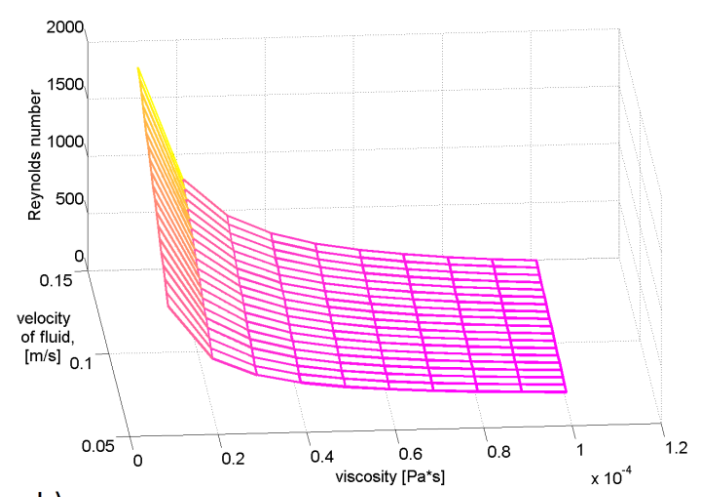

b)

Fig. 6. a) Dependency of fluid velocity $(\mathrm{mm} / \mathrm{s})$ on viscosity $(\mathrm{Pa} \cdot \mathrm{s})$ and fluid thickness $(\mathrm{mm})$ at constant density $\left(\mathrm{kg} / \mathrm{m}^{3}\right)$.

b) Influence of viscosity $(\mathrm{Pa} \cdot \mathrm{s})$ and velocity of fluid $(\mathrm{m} / \mathrm{s})$ on Reynolds number (dimensionless) at constant density $\left(\mathrm{kg} / \mathrm{m}^{3}\right)$ and thickness $\left(1.45 \times 10^{-4} \mathrm{~m}\right)$ 
Once the value of film thickness is known, Reynolds number can be evaluated after $\operatorname{Re}=(\bar{v} \delta \rho) / \mu$, as mentioned previously. Fig. 6b) describes the variation of Reynolds number with viscosity and velocity of fluid at constant density and thickness $\left(1.45 \times 10^{-4} \mathrm{~m}\right)$. This plot is important because it allow us to differentiate clearly the conditions of viscosity and fluid velocity for which the fluid is laminar, in transition or turbulent. For the particular case of analysis, the numerical parameters selected describe a laminar flow as Reynolds number is below 2300.

Particularly, for viscous systems, it is important to consider particular values of flow velocities depending on the piping design (pipe dimensions).

After evaluation of Prandtl and Reynolds number, it is possible to determine Nusselt formula given the numerical values of constants $C$ and $m$ from equation $N u=C \cdot \operatorname{Pr}^{0.35} \operatorname{Re}^{m}$. Convection is more efficient as Nusselt number increases. Modeling by means of dimensionless numbers is of great importance in heat transfer systems because it can describe real physical problems as it is possible to observe fluid behavior under change in particular physical systems at different values of Prandtl number (type of fluid and information about the thickness of thermal and hydrodynamic or velocity boundary layer), Reynolds number (i.e. turbulence or steady flow), different Nusselt number and observing the velocity trend relative to specific values of Reynolds number (whether conduction or convection is the dominant parameter)

Prandtl number will strongly be dependent upon the temperature, thus for example; motor oil can have a value of about 116 at $140{ }^{\circ} \mathrm{C}$ and 10400 at $20^{\circ} \mathrm{C}$. This is due to the variation of thermal properties at different temperature, i.e. density, dynamic viscosity and cinematic viscosity. The higher values shown that convection is very efficient in heat transfer compare to conduction, which is characteristic of fluids with high viscosity. For gases, non-metal fluids and non-viscous fluids, the order of magnitude is generally one and the magnitude of this parameter will vary very little with changes of temperature and pressure. In mercury, for example, heat conduction is very effective compared to convection, as a result Prandtl number will have a low value [18].

For comparison purposes, we present in Table 1 the values of heat transfer coefficient calculated for different type of fluids. The highest estimated value was for acetone $\left(8352 \mathrm{~W} / \mathrm{m}^{2} \cdot \mathrm{K}\right)$, followed by chloroform $\left(7008 \mathrm{~W} / \mathrm{m}^{2} \cdot \mathrm{K}\right)$. The lowest value was $3048 \mathrm{~W} / \mathrm{m}^{2} \cdot K$, corresponding to phenol. The constant values of $c$ and $m$ used in the calculations were 0.86 and 0.41 respectively for all the compounds, except for phenol, which was 0.99 and 0.305 due to the lowest $R e$ value. Acetone presented also the highest value of fluid velocity $(0.1 \mathrm{~m} / \mathrm{s})$. Reynolds number was less than 2100 , therefore the flow was laminar in all cases.

\begin{tabular}{|c|c|c|c|c|c|c|c|c|c|c|c|c|}
\hline substance & $\begin{array}{c}\boldsymbol{\rho} \\
\left(\mathbf{k g} / \mathbf{m}^{3}\right)\end{array}$ & $\begin{array}{c}\boldsymbol{\mu} \\
(\boldsymbol{P a} \cdot \boldsymbol{s})\end{array}$ & $\begin{array}{c}\boldsymbol{v} \\
\left(\mathbf{m m}^{\mathbf{2}} / \mathbf{s}\right)\end{array}$ & $\begin{array}{c}\boldsymbol{\lambda} \\
(\boldsymbol{W / m} \cdot \mathbf{K})\end{array}$ & $\begin{array}{c}\boldsymbol{C}_{\boldsymbol{p}} \\
(\mathbf{J} / \mathbf{k} \cdot \mathbf{K})\end{array}$ & $\begin{array}{c}\boldsymbol{a} \\
\left(\mathbf{m m}^{2} / \mathbf{s}\right)\end{array}$ & $\boldsymbol{P r}$ & $\begin{array}{c}\boldsymbol{\delta} \\
(\mathbf{m m})\end{array}$ & $\begin{array}{c}\overline{\boldsymbol{v}} \\
(\boldsymbol{m} / \mathbf{s})\end{array}$ & $\boldsymbol{R e}$ & $\boldsymbol{N u}$ & $\begin{array}{c}\boldsymbol{\alpha} \\
\left(\boldsymbol{W} / \boldsymbol{m}^{2} \cdot \mathbf{K}\right)\end{array}$ \\
\hline Acetone & 784 & 0.0003 & 0.4 & 0.168 & 2150 & 0.099 & 4.04 & 0.20 & 0.10 & 31 & 5.78 & 8352 \\
\hline $\begin{array}{c}\text { Propyl } \\
\text { alcohol }\end{array}$ & 800 & 0.0019 & 2.3 & 0.161 & 2370 & 0.084 & 27.9 & 0.14 & 0.06 & 5.2 & 5.45 & 4207 \\
\hline Acetic acid & 1049 & 0.001 & 0.95 & 0.193 & 2043 & 0.09 & 10.5 & 0.27 & 0.07 & 10 & 5.04 & 6930 \\
\hline Phenol & 1072 & 0.008 & 7.46 & 0.19 & 1430 & 0.12 & 60.2 & 0.08 & 0.03 & 1.2 & 4.44 & 3048 \\
\hline Chloroform & 1489 & 0.0005 & 0.33 & 0.129 & 1050 & 0.082 & 4.07 & 0.14 & 0.08 & 20 & 4.80 & 7008 \\
\hline Water & 1000 & 0.001 & 1 & 0.1 & 4180 & 0.023 & 41.8 & 0.20 & 0.07 & 10 & 8.16 & 5624 \\
\hline
\end{tabular}

Table 1. Determination of heat transfer coefficient using the derived equations for different type of fluids at constant values of $\dot{m}=0.01 \mathrm{~kg} / \mathrm{s}$, and $b=1 \mathrm{~m}$

Finally, we used computational fluid dynamics to describe the process of mass transfer in a fluid running down a surface. We used Comsol multiphysics software to model the system. Chemical species transport interface (transport of dilutes species interface) was used to compute the concentration field of a dilute solute in a solvent. The second set of equations required involved momentum transfer, therefore we used fluid flow interface (single-phase flow in laminar regime) to simulate flow and pressure fields of liquids and gases. The system was studied in 2D space dimension. We can observe the concentration distribution in Fig. 7 a). Considering the interface in the right side the concentration is maximum, while on the left side tend to decrease towards zero.

The velocity profile is presented in Fig. 7 b). Here, the highest value are also on the right side and decrease along the surface of the wall. Concentration profile and velocity profile across the thickness of the surface layer are presented in Fig 7 c) and Fig 7 d) respectively for a selected area. The physical interfaces added to the system were laminar flow and transport of diluted species in stationary state operation (field variables do not change over time). For modeling purposes, water was selected as the fluid. The equations solved by the laminar flow were the Navier-Stokes equations for conservation of momentum and the continuity equation for conservation of mass. In shell momentum balance (steady state), one important parameter is to determine the velocity profile as a function of space. Boundary conditions, inlet, outlet and wall surface were defined. It was considered the flow of a gas on the right side. Diffusion coefficient was defined as $1 \times 10^{-7} \mathrm{~m}^{2} / \mathrm{s}$. The bottom part of the surface was selected as the outflow and the upper part the inflow. Computational fluid dynamics is widely used in modeling of a diversity of engineering systems. Similar analysis can be performed to model the case of a water tank filling system. Once the reservoir is completely full, the water will start running down a surface layer. 
Initially there will be variation in time until steady state is achieved and the fluid velocity depends on only one variable $\left(v_{z}(x)\right)$ in case of incompressible fluids and the continuity equation for steady state situation that express the rate of change of velocity $v_{z}$ with respect to $z$ is zero $\left(\partial v_{z} / \partial z=0\right)$. In fact, this would also probably remains in non steady state because density will be still a constant, so the derivative with respect to any variable, not just time will be zero $(\nabla \cdot \rho v+\partial \rho / \partial t=0)$. In this case, we do not expect much variation along y-axis, or in other words, packets of fluid that are moving along at the left end do not differ significantly from packets of fluid that are moving along towards the center of the flow versus those moving along the right end as there is a very thin film of fluid which is in contact with air and the shear stress associated with a gas-liquid interface would be negligible. In this type of system there would be uniform distribution of velocity along the left and right side ( $y$-axis). On the contrary, variation along the $x$ axis would be expected due to no-slip boundary condition at the surface.
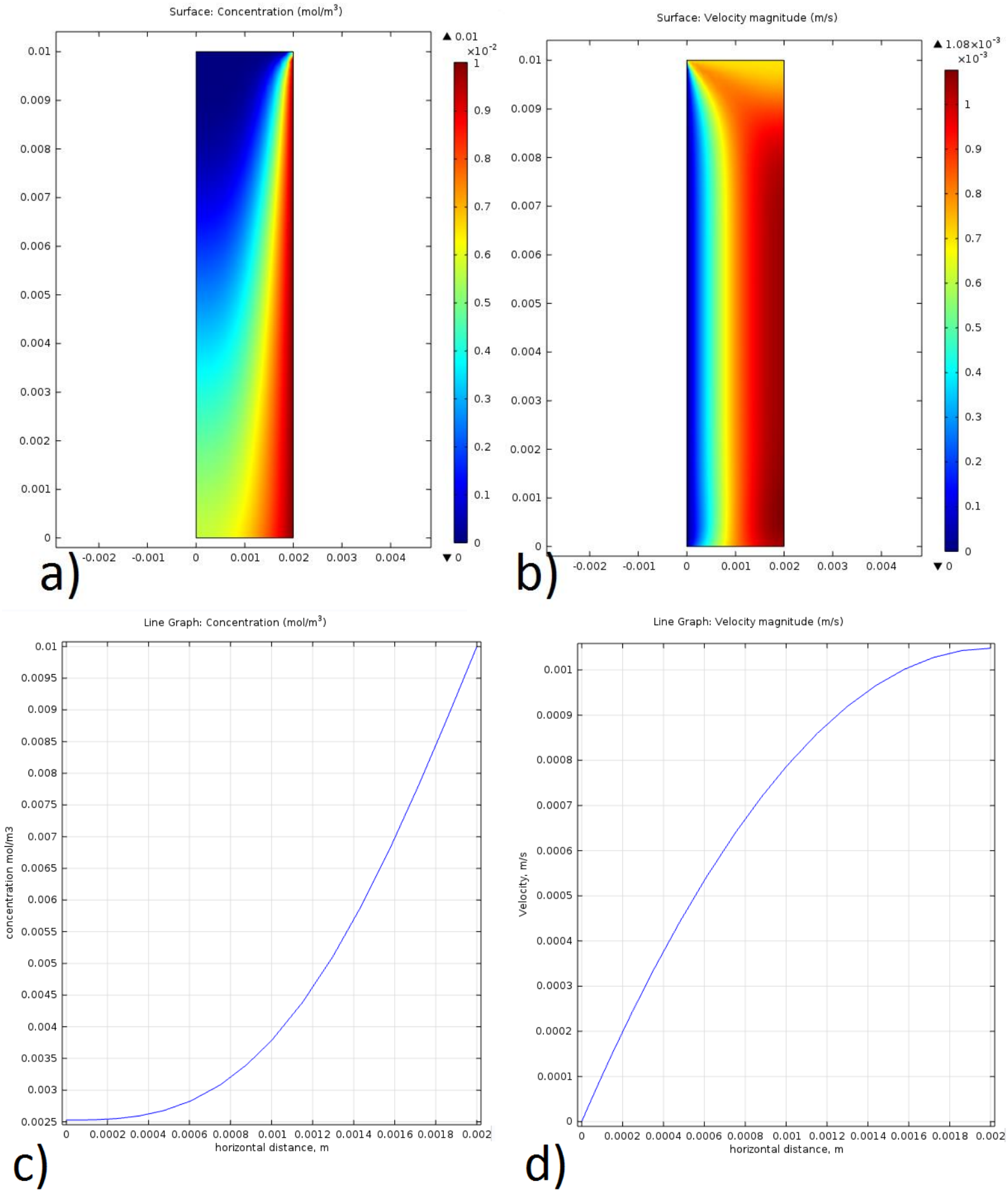

Fig. 7. Concentration profile and velocity profile across the thickness of the surface layer a) and b) correspond to surface distribution while c) and d) refer to data set points 


\section{Conclusions}

The study of fluids in motion and the understanding of their physico-chemical properties and behavior are important in unit operations and process engineering. The behavior of fluids constitutes one of the foundations for the study of unit operations. Knowledge of fluids is essential, not just to understand the problems of fluid movement through pipes, pumps and other types of equipment, but also for the study of heat flow and many operations that require separation and depend on mass diffusion and transfer. When a fluid is going through a pipe, it can follow low or higher speeds. At low fluid speeds, the movement has a laminar character. However when there are higher speeds, the flow of the fluid is disorganized thus obtaining a turbulent flow. Reynolds number is a dimensional parameter that defines the flow characteristics within a pipe. Additionally, it also expresses the loss of energy caused by viscous effects. Analysis of physical problems using dimensionless numbers is a useful tool because it allows us to study scaled down models to simulate the real system. Additionally, providing that we have real data of the system we could validate the numerical model developed to run several test of the system which in other cases would be expensive, not practical or complicated.

The present study forms a base for further studies, particularly for cases of fluid injection in oscillatory flow columns, falling-film column, coating, flow of viscous fluids through a vertical glass funnel, and optimal design of pumping stations. These results can be also complemented by determining friction factor using the Moody chart, Colebrook equation or explicit Haaland relation. This parameter is useful in estimating pressure drop in pipes and pumping power required, which is basically the mechanical power that needs to be imparted to the fluid. This power has not to be confused with shaft power or electrical power, which will be more due to pump and motor inefficiency respectively. We have studied mathematical expressions that allow us to understand the relationship between several physic-chemical properties of the fluid. Although the studied system involved a vertical surface, it can be slightly modified by including the surface angle $\theta$, it can also be complemented with mass transfer analysis to model the adsorption of gas into a falling film liquid by using motion equations, mass transfer equations and the coupled mass and momentum transport equations. Furthermore, numerical solution of these equations could be easily achieved by means of finite element analysis. We motive eager younger researchers to deep within this approach of mathematical modeling and numerical simulation of engineering systems and processes.

\section{Acknowledgments}

This work was supported by the Ministry of Education, Youth and Sports of the Czech Republic within the National Sustainability Programme project No. LO1303 (MSMT-7778/2014).

\section{References}

[1] Geankoplis, C. (1993). Transport processes and unit operations, Prentice Hall, ISBN 978-0131013674, New Jersey, USA.

[2] Bakhtiyarov S. \& Overfelt RA (1999). Measurement of liquid metal viscosity by rotational technique. Acta Materialia Vol. 47, No. 17, pp. 4311-4319., doi: 10.1016/S1359-6454(99)00307-9

[3] Cengel Y, \& Turner R (2001). Fundamentals of Thermal-Fluid Sciences, McGraw-Hill Higher Education, ISBN 978-0078027680, Singapore.

[4] Bird R.; Stewart E.; \& Lightfoot NE (2002). Transport Phenomena, John Wiley \& Sons, Inc, ISBN 9780470115398 New York.

[5] Hantsch A. \& Gross U (2013). Numerical Simulation of Falling Liquid Film Flow on a Vertical Plane by TwoPhase Lattice Boltzmann Method. Journal of Engineering Vol. 2013, pp. 1-9., doi: 10.1155/2013/484137

[6] Miyara A. (2001). Flow Dynamics and Heat Transfer of Wavy Condensate Film. Journal of Heat Transfer Vol. 123, No.3. pp.492-500., doi: 10.1115/1.1370522

[7] Miyara A. (2000). Numerical simulation of wavy liquid film flowing down on a vertical wall and an inclined wall. International Journal of Thermal Sciences Vol. 39, No.9-11, pp. 1015-1027., doi: 10.1016/S1290-0729(00)011923

[8] Lavalle G,; Vila J \& Blanchard G. (2015). A numerical reduced model for thin liquid films sheared by a gas flow. J Comput Phys 301:119-140. doi: 10.1016/J.JCP.2015.08.018

[9] Kuzmin, A; Popov V \&, Stazhkov S (2016). Rotation Transmission Device in High Ambient Hydrostatic Pressure Conditions. Chapter 22 DAAAM Int Sci B. doi: 10.2507/daaam.scibook.2016.22

[10] Kovacs, A \& Kovacs L (2011). Analyzing the fluid motion through network profiles using the boundary element method. Annals of DAAAM for 2011 \& Proceedings of the 22nd International DAAAM Symposium, Vol. 22, No.1, pp.1147-1148., ISSN 1726-9679

[11] Kovacs, A \& Kovacs L (2012). A hodographic approximation method for analyzing the fluid motion through network profiles. Annals of DAAAM for 2012 \& Proceedings of the 23rd International DAAAM Symposium, Volume 23, No.1,pp. 125-128., ISSN 2304-1382 
[12] Muminovic A.; Repcic N, \& Colic M. (2014). Thermo Elasto Hydrodynamic Lubrication Model of Mixed Friction. Procedia Engineering in 24th DAAAM International Symposium of Intelligent Manufacturing and Automation, 2013, Katalinic B. (Ed.) Vol. 69, pp.49-56. doi: 10.1016/J.PROENG.2014.02.202

[13] Edin B. \& Šefko Š. (2015). Computational Modeling and Simulation of Nonisothermal Free-surface Flow of a Liquid Jet Impinging on a Heated Surface. Procedia Engineering in 25th DAAAM International Symposium of Intelligent Manufacturing and Automation 2014, Katalinic B. (Ed.), Vol. 100, pp.115-124. doi: 10.1016/J.PROENG.2015.01.349

[14] Mateescu T.; Cotorobai V. \& Mare T. (1991). Nusselt Number and Convection Heat Transfer Coefficient for a Coaxial Heat Exchanger Using A12O3-Water pH=5 Nanofluid, The Bulletin of the Polytechnic Institute of Jassy. Vol. LV(LIX), No.2, pp.71-80.

[15] Yarmand H.; Gharehkhani S. \& Kazi S. (2014). Numerical investigation of heat transfer enhancement in a rectangular heated pipe for turbulent nanofluid. The Scientific World Journal, Vol. 2014, No. 369593. pp.1-9, doi: $10.1155 / 2014 / 369593$

[16] Herwig H. (2016). What Exactly is the Nusselt Number in Convective Heat Transfer Problems and are There Alternatives? Entropy, Vol. 18, No. 5, pp.1-15. doi: 10.3390/e18050198

[17] Kedzierski M. (2013). Viscosity and density of aluminum oxide nanolubricant. International Journal of Refrigeration Vol. 36, No 4. pp.1333-1340. doi: 10.1016/J.IJREFRIG.2013.02.017

[18] Coulson J.; Richardson J. \& Backhurst JR, (1999). Chemical engineering. Vol. 1, Fluid flow, heat transfer and mass transfer, Butterworth-Heinemann ISBN 9780750644440 , Oxford. 